TITLE:

\title{
Germination characteristics of four common perennial grasses of Inner Mongolian grassland, China
}

$\operatorname{AUTHOR}(S)$ :

Ao, Min; Miura, Reiichi; Tominaga, Tohru

\section{CITATION:}

Ao, Min ... [et al]. Germination characteristics of four common perennial grasses of Inner Mongolian grassland, China. Grassland Science 2014, 60(1): 9-14

ISSUE DATE:

2014-02-17

URL:

http://hdl.handle.net/2433/197335

\section{RIGHT:}

This is the peer reviewed version of the following article: Ao, M., Miura, R. and Tominaga, T. (2014), Germination characteristics of four common perennial grasses of Inner Mongolian grassland, China. Grassland Science, 60: 9-14, which has been published in final form at http://dx.doi.org/10.1111/grs.12043; This is not the published version. Please cite only the published version; この論文は出版社版でありません。引用の際には出版社版をご確認ご利用ください。 
1 Short running title: Germination of Inner Mongolian grasses

2

3 Germination characteristics of four common perennial grasses of Inner

4 Mongolian grassland, China

5

6 Min Ao, Reiichi Miura and Tohru Tominaga

7

8

9 Graduate School of Agriculture, Kyoto University, Kyoto, Japan

10

11

12

13

14

15 Correspondence

16 Reiichi Miura, Graduate School of Agriculture, Kyoto University, Kyoto 606-8502,

17 Japan.

18 E-mail: miurar@kais.kyoto-u.ac.jp

19 Tel.: +81-(0)75-753-6066

$20 \quad$ Fax.: +81-(0)75-753-6062

21 


\section{Abstract}

2

3 The grassland of Inner Mongolia, China, has experienced a decrease in area. To provide

4 useful information for artificial grassland restoration, the germination characteristics of

5 four native grass species, Leymus chinensis (Trin.) Tzvel., Agropyron cristatum (L.)

6 Gaertn., Bromus inermis Leyss., and Elymus dahuricus Turcz., were compared under

7 laboratory conditions. The seeds of $A$. cristatum and B. inermis showed $>70 \%$

8 germination at a wide range of temperatures from 10 to $30^{\circ} \mathrm{C}$ with or without light.

9 Seeds of E. dahuricus did not show clear dormancy, but required a rather high

10 temperature $\left(20-30^{\circ} \mathrm{C}\right)$ for germination. When the temperature was alternated between

11 day and night, it was the higher of the temperatures (the daytime temperature) that

12 largely determined the percentage of germination. The germination of E. dahuricus was

13 higher (max. 87\%) in darkness than in light (max. 58\%). Intact seeds of L. chinensis

14 showed considerable germination (47\%) under a wide range of temperatures $\left(30 / 10^{\circ} \mathrm{C}\right)$.

15 Additionally, the dehusking of L chinensis seeds improved the germinability at a

16 constant temperature. These results are suggestive of a different regeneration niche

17 among the four species, which should be taken into account when selecting the species

18 and method for grassland restoration.

\section{Introduction}

24 The grassland in Inner Mongolia, China, has decreased in area and deteriorated over the 
1 past 50 years due to increased human disturbance (Meyer 2006; Ito et al. 2006;

2 Akiyama and Kawamura 2007; Kawada et al. 2011). Current efforts, including the

3 banning of grazing and artificial grassland restoration, have not reversed this trend

4 (Jiang et al. 2006; Meyer 2006). The development of reliable technology for vegetation

5 restoration is of primary importance in this area.

6 In northeastern Inner Mongolia, Leymus chinensis (Trin.) Tzvel. (Aneurolepidium

7 chinense [Trin.] Kitag.), is the most dominant species of the typical steppe under

8 adequate grazing pressure, and is a source of high-quality forage (Yiruhan et al. 2001;

9 Liu et al. 2004; Kawada et al. 2011). Studies to improve or restore the grassland 10 through artificial seed sowing have focused on this species. However, there are many 11 other wild or cultivated species that could also be useful in restoration trials, including 12 Agropyron cristatum (L.) Gaertn., Bromus inermis Leyss., and Elymus dahuricus Turcz. 13 (Shao et al. 2006). At our study site in northeastern Inner Mongolia, A. cristatum and B. 14 inermis are found in more heavily grazed or disturbed habitats than L. chinensis (Ao et 15 al. 2008). In addition, E. dahuricus is resistant to extreme winter temperatures and 16 adverse soil conditions (Kawada et al. 2011).

17 Knowledge of the ecophysiology in each aspect of the life cycle of the utilized 18 species is essential for successful grassland restoration. In a previous report (Ao et al. 19 2009), we examined the underground architecture of these four species (including $L$. 20 chinensis). All of the species are perennials, but they showed characteristic underground 21 architectures: A. cristatum and E. dahuricus lacked rhizomes and formed separate 22 bunches, $B$. inermis produced many short rhizomes, and $L$. chinensis produced fewer and longer rhizomes (Ao et al. 2009).

24 In this report, we describe the germination characteristics of the above four species. 
1 Agropyron cristatum and B. inermis were introduced to North America in the late $19^{\text {th }}$ or

2 early $20^{\text {th }}$ century, and their cultivars have been extensively used for rangeland

3 improvement (Newell 1973; Rogler 1973). Accordingly, there are many reports on the

4 germination characteristics of these introduced grasses in the US and Canada (Plummer

5 1943; Ashby and Hellmers 1955; McGinnies 1960; Smoliak and Johnston 1968;

6 McElgunn 1974; Grilz et al. 1994). However, many of these materials have already

7 been subjected to artificial selection (Smoliak and Johnston 1968), hence these results

8 may not be applicable to wild strains in their native area. Elymus dahuricus and $L$.

9 chinensis are rarely used outside their native range. In China, the poor germination of $L$.

10 chinensis has been regarded as an obstacle to artificial stand establishment (Liu et al.

11 2004; Zhang et al. 2006; Ma et al. 2008). This low germination rate was somewhat

12 improved in the cultivated strain, but it was accompanied by low survival rates and

13 biomass production (Liu and Han 2008).

14 To develop an ecology-based strategy for grassland restoration, it is important to 15 compare the germination traits of useful candidate species under common conditions.

16 Here, we examined the effects of constant and alternating temperatures and light on the 17 germination of A. cristatum, B. inermis, E. dahuricus, and L. chinensis. We also examined whether dehusking and scarification could improve the low germination rate of L. chinensis.

\section{Materials and methods}

\section{Seed material}


1 Caryopses with the lemma and palea (hereafter "seeds") of four grass species, $A$.

2 cristatum, B. inermis, E. dahuricus, and L. chinensis, were collected from the grassland

3 at Beishan Experiment Station, Hailaer $\left(49^{\circ} 13^{\prime} \mathrm{N}, 119^{\circ} 45^{\prime} \mathrm{E} ; 611 \mathrm{~m}\right.$ above sea level), in

4 the northeast region of Inner Mongolia, China, in August of 2006 and 2007. The seeds

5 were winnowed, dried, and stored at $5{ }^{\circ} \mathrm{C}$ until the four germination experiments, as

6 described below.

7

\section{Experiment 1. Germination at a constant temperature}

9 Seeds collected in 2007 were used. The seeds were sown on $0.8 \%$ agar beds of cells in 10 transparent plastic boxes on October 11, 2007, and kept in incubators (Type NS60;

11 Takayama Manufacturing, Kyoto, Japan) at 5, 10, 15, 20, 25, and $30^{\circ} \mathrm{C}$. One pair of 12 boxes for each temperature was kept under a 12-h photoperiod under white fluorescent 13 light, with the daytime light intensity set at approximately $20 \mu \mathrm{mol} \mathrm{s}{ }^{-1} \mathrm{~m}^{-2}$ (400-700 $14 \mathrm{~nm})$. The other box was kept in darkness by wrapping the box with aluminum foil and two layers of silver PVC film immediately after sowing.

\section{Experiment 2. Germination at alternating temperatures}

18 Seeds collected in 2007 were used. The procedure was the same as in Experiment 1, 19 except that the seeds were sown on January 8, 2008, and kept in incubators at three 20 constant $\left(10,20\right.$, and $\left.30^{\circ} \mathrm{C}\right)$ and three alternating $\left(20 / 10,30 / 10\right.$, and $\left.30 / 20^{\circ} \mathrm{C}\right)$ 21 temperatures (with a 12-h photoperiod), with the higher temperature corresponding to 22 the daytime (illuminated) period for the alternating temperatures.

\section{Experiment 3. Germinability and viability of 1-year-old and current-year seeds}


1 Seeds collected in August 2006 and August 2007 were sown on December 7, 2007, to

2 examine the effect of seed aging on germinability. Germination was tested at $25^{\circ} \mathrm{C}$

3 under light only. The procedure otherwise followed that of Experiment 1 . Seeds

4 remaining ungerminated on the final day of the germination test were cut longitudinally

5 in half and subjected to the triphenyl tetrazolium chloride test, as described in

6 McDonald and Copeland (1989) to evaluate their viability.

7

\section{Experiment 4. Effect of dehusking and scarification of Leymus seeds}

9 Seeds of $L$. chinensis collected in 2007 were used. A batch of dried seeds were 10 dehusked with tweezers. The short axis bearing the lemma and palea was also removed

11 from the caryopsis. Another batch of seeds were imbibed for $16 \mathrm{~h}$ at room temperature 12 and then pierced with a thin sowing needle in the middle part of the "seed" (i.e., through 13 the endosperm). The dehusked, scarified, and intact seeds were sown on a $0.8 \%$ agar 14 bed of cells in transparent plastic boxes on March 12, 2008, and kept in incubators at 15 three constant temperatures $\left(10,20\right.$, and $\left.30^{\circ} \mathrm{C}\right)$ and three alternating temperatures $16\left(20 / 10,30 / 10\right.$, and $\left.30 / 20^{\circ} \mathrm{C} ; 12 / 12 \mathrm{~h}\right)$. The procedure otherwise followed that of 17 Experiment 1.

18 In all experiments, four replicates of 30 seeds were used for each condition or 19 treatment. The test was continued for three weeks and germinated seeds were counted 20 and removed daily. The boxes kept in darkness were opened on the final day only.

21 Radicle emergence was used as the criterion for germination.

\section{Statistical analysis}

23 The germination count data were subjected to a logistic regression analysis using the

24 glm function of the statistical software package R 2.8.0 (R Development Core Team 
1 2008). When large overdispersion was observed, the quasibinomial error distribution

2 was applied. When multiple comparisons were required, the data were subjected to

3 Tukey’s HSD test using the Multcomp View package in R (Graves et al. 2006) after

4 arcsin transformation.

$5 \quad$ When analyzing germination at alternating temperatures (Experiment 2), logistic

6 regression in an ANOVA-like manner was not performed because the combination

7 between day and night temperatures was not completely factorial (i.e., the lack of

8 combinations with higher temperatures at night). Instead, the percentage germination at

9 each combination of day/night temperatures was arcsin-transformed and compared

10 using Tukey's HSD test at the 5\% significance level.

Results

\section{Experiment 1. Germination at a constant temperature}

15 Time courses of seed germination for the four grass species at six constant temperatures $16\left(5,10,15,20,25\right.$, and $\left.30^{\circ} \mathrm{C}\right)$ under a 12-h photoperiod are shown in Figure 1.

17 Agropyron cristatum and $B$. inermis started germination on the third day after sowing, and most of the germination occurred within nine days from sowing, except at the lowest temperature $\left(5^{\circ} \mathrm{C}\right)$. The final percentage of germination was between 70 and $100 \%$ in both species (except at $5^{\circ} \mathrm{C}$ ). In $E$. dahuricus, germination started on the fourth

21 day after sowing at the highest temperatures (25 and $\left.30^{\circ} \mathrm{C}\right)$ and continued through the

22 third week, but did not exceed 60\%. In L. chinensis, sporadic germination was observed at these constant temperatures.

24 The influences of temperature and light on the germination of the four species are 
1 shown in Figure 2. A logistic regression analysis incorporating the interaction between

2 the effects of temperature and light showed a significant interaction $(\mathrm{P}<0.05)$ only in $A$.

3 cristatum. Thus, the other three species were analyzed again without including the

4 interaction term.

5 In A. cristatum, a final percentage of germination of approximately $90 \%$ was

6 reached at $10-30^{\circ} \mathrm{C}$, where no significant effect of light was observed. The germination

7 in darkness was as low as $16.7 \%$ at $5^{\circ} \mathrm{C}$. In $B$. inermis, the percentage of germination at

$8 \quad 10-30^{\circ} \mathrm{C}$ ranged from 75 to $90 \%$, but was much lower at $5^{\circ} \mathrm{C}(13.3 \%$ under a $12-\mathrm{h}$

9 photoperiod and $0.8 \%$ in darkness). The effect of temperature was highly significant (P

$10<0.001)$, but the effect of light was not $(\mathrm{P}=0.55)$. In E. dahuricus, the effects of

11 temperature and light were both highly significant $(\mathrm{P}<0.001)$ and the final percentage

12 of germination was much higher in darkness than under a 12 -h photoperiod at $15-30^{\circ} \mathrm{C}$.

13 A maximum germination rate of $86.7 \%$ was observed at $25^{\circ} \mathrm{C}$ in darkness. Negligible

14 germination was observed at 5 and $10^{\circ} \mathrm{C}$. The percentage of germination of L. chinensis

15 was very low at all constant temperatures, regardless of the light conditions, with the

16 maximum germination being $6.7 \%$ at $25^{\circ} \mathrm{C}$ under a 12 -h photoperiod.

17 Since germination was exceptionally low at $5^{\circ} \mathrm{C}$ in $A$. cristatum and $B$. inermis, the 18 data were re-analyzed at $10-30^{\circ} \mathrm{C}$. The effect of light was again insignificant $(\mathrm{P}>0.05)$

19 in A. cristatum, but the germination of $B$. inermis was significantly higher $(\mathrm{P}<0.001)$ in

20 darkness than under a 12-h photoperiod in this temperature range.

21

22 Experiment 2. Germination at alternating temperatures

23 The effects of alternating temperature on the germination of the four species are shown

24 in Figure 3. Agropyron cristatum showed high rates of germination at all temperatures, 
1 with the lowest germination being $89.3 \%$; thus, no significant effect of alternating

2 temperature was observed. In $B$. inermis, the percentages of germination at three

3 alternating temperatures (95-98\%) were not significantly different from those at 20 or

$430^{\circ} \mathrm{C}$. Elymus dahuricus showed the highest germination of $98.3 \%$ at the alternating

5 temperature of $30 / 10^{\circ} \mathrm{C}$, which was significantly higher $(\mathrm{P}<0.05)$ than the highest

6 value at a constant temperature $\left(87.5 \%\right.$ at $\left.30^{\circ} \mathrm{C}\right)$. Leymus chinensis showed considerable

7 germination only at alternating temperatures $\left(46.7 \%\right.$ at $30 / 10^{\circ} \mathrm{C}$ and $15.8 \%$ at $\left.30 / 20^{\circ} \mathrm{C}\right)$.

8

9 Experiment 3. Germinability and viability of 1-year-old and current-year seeds

10 The difference in germinability between 1-year-old and current-year seeds varied

11 between species, showing a significant interaction between species and seed age $(\mathrm{P}<$

12 0.01; Figure 4). A separate analysis for each species showed significant differences

13 between the two seed lots $(\mathrm{P}<0.05)$ only in $A$. cristatum. The lower germination rate of

14 the 1-year-old seeds of $A$. cristatum was due to the increase in the percentage of dead

15 seeds; the percentage germination based on the number of viable seeds was not

16 significantly different between the two lots $(\mathrm{P}=0.99)$. The percentage of dead seeds

17 was significantly higher in 1-year-old seeds than in current-year seeds for all species (P

$18<0.001)$

20 Experiment 4. Effect of dehusking and scarification of Leymus seeds

21 The effects of dehusking and scarification on the germination of L. chinensis are shown

22 in Figure 5. The effects of the seed treatments and temperature, as well as their 23 interactions, were all significant $(\mathrm{P}<0.001)$ according to a logistic regression analysis.

24 The percentage germination was highest in dehusked seeds at any temperature where at 
1 least some germination occurred. However, the differences among the seed treatments

2 were not significant $(\mathrm{P}=0.056)$ at $30 / 10^{\circ} \mathrm{C}$ where scarified and control seeds also

3 showed high germination rates.

4

5 Discussion

6

$7 \quad$ Seed viability

8 Experiment 3 showed that the viability of current-year seeds was greater than $90 \%$ in all

9 species (Figure 4). Thus, data correction taking seed viability into account was not

10 required in the germination test among current-year seeds. There was a general trend

11 towards decreased viability in 1-year-old seeds, suggesting that longer-term storage

12 before sowing may be detrimental.

13

\section{Germination characteristics of $A$. cristatum and B. inermis}

15 The seeds of $A$. cristatum and B. inermis did not show considerable dormancy, but did 16 show high germination rates at temperatures between 10 and $30^{\circ} \mathrm{C}$ with or without light

17 (Figure 2). They likely germinate quickly when receiving sufficient amounts of rain.

18 This is a crop-like trait that would make these species easy to use for artificial grassland

19 restoration. Many studies conducted in North America, where introduced A. cristatum

20 and B. inermis have been widely used for grassland establishment or improvement,

21 reported that the seeds of these species did not show considerable dormancy and

22 germinated under a wide range of both constant and alternating temperatures (Plummer

23 1943; Ashby and Hellmers 1955; McGinnies 1960; Smoliak and Johnston 1968;

24 McElgunn 1974; Grilz et al. 1994). The lack of seed dormancy reported of these species 
1 is probably not the consequence of domestication, but rather one of the reasons why

2 they were chosen among many wild grass species.

3 Agropyron cristatum is a bunch-forming grass lacking rhizomes, whereas $B$. inermis

4 is a sod-forming grass that propagates both via rhizomes and seeds (Ao et al. 2009).

5 Although they showed similar germination characteristics, the role of propagation via

6 seeds in the whole population cycle differs between these species. To adequately

7 interpret their germination strategy, more information is required on other aspects of

8 their life cycle (e.g., seed dispersal and seed bank dynamics).

10 Germination characteristics of $\boldsymbol{E}$. dahuricus

11 The seeds of E. dahuricus did not show clear dormancy, but had a more specific 12 requirement for germination than $A$. cristatum or $B$. inermis. The seeds had a rather high 13 optimum temperature range $\left(20-30^{\circ} \mathrm{C}\right)$ for germination (Figure 2), and if the 14 temperature was alternated between day and night, it was the higher of the temperatures 15 (i.e., the daytime temperature) that largely determined the percentage of germination 16 (Figure 3). This requirement for a higher temperature may at first appear inconsistent 17 with the low-temperature hardiness reported for this species. However, this germination requirement may be an adaptation to avoid suicidal germination late in the growing season. It is important to examine whether this species regularly forms an overwintering seed bank in the field.

21 The germination of E. dahuricus was moderately reduced in the presence of light 22 (Figure 2). Bewley and Black (1982) and Baskin and Baskin (2001) presented numerous examples of light requirements for germination (positive photoblastism)

24 among diverse seed plants, but few examples of germination inhibition by white light 
1 (negative photoblastism) are available. The ecological function of negative

2 photoblastism is not well understood (Pons 2000). Under the semi-desert climatic and

3 edaphic environment of Inner Mongolia, seedlings germinating on the soil surface are

4 likely prone to drought. The suppression of germination by light may also be an

5 adaptation to reduce the risk of germinating under unsafe situations.

6

$7 \quad$ Germination characteristics of $L$. chinensis

8 Leymus chinensis showed very different germination characteristics compared to the

9 other species. Without seed pretreatment, this species germinated only under a wide

10 fluctuation of temperature (Figure 3). These results are in general agreement with those

11 reported previously (Liu et al. 2004; Ma et al. 2012). Leymus chinensis is a dominant

12 species of the natural grassland of this area, and forms a dense sod through its extensive

13 rhizome system (Ao et al. 2009). Liu and Han (2007) experimentally showed that a

14 vegetation gap is required for the successful emergence and establishment of $L$.

15 chinensis seedlings, and they reported that the requirement for a fluctuating temperature

16 for germination is a gap-detecting mechanism. Under fluctuating temperatures, the

17 percentage germination increased gradually during the latter half of the experiment

18 (data not shown), suggesting that the effect of temperature fluctuations may be to break

19 dormancy rather than induce germination.

20 There have been contradictory reports on the effect of dehusking on seed

21 germination in L. chinensis. Liu et al. (2004) observed no significant effect of 22 dehusking, while Ma et al. (2008) reported that dehusking moderately increased both 23 the speed and final percentage of germination. In our experiment, the dehusking of $L$.

24 chinensis seeds considerably improved their germinability (Figure 5). Ma et al. (2008) 
1 also compared germination between dehusked seeds and seeds that were replaced in the

2 husks after dehusking, and concluded that the seed dormancy of this species is due to

3 mechanical (but not chemical) effects of the husk. Since scarification alone did not

4 significantly improve germination in our experiment, this "mechanical" effect is not

5 likely due to impermeability of the seed coat. Although the exact role of the husk on

6 seed dormancy remains unclear, these results suggest that, if a reliable method for seed

7 dehusking could be developed, it would improve the efficiency of the artificial

8 restoration of $L$. chinensis stands through seed sowing.

\section{Acknowledgments}

12 We are grateful to Hailaer District's Grassland Bureau, Hulunbeir City's Grassland

13 Bureau and Ewenke Prefecture's Grassland Bureau for their kind help in our collecting 14 of materials, and Dr. Y. Shimono, Kyoto University, for her help in statistical analysis. 15 We also thank two anonymous reviewers for their helpful comments on the earlier 16 manuscript.

\section{References}

20 Akiyama T, Kawamura K (2007) Grassland degradation in China: methods of 21 monitoring, management and restoration. Grassl Sci 53: 1-17.

22 Ao M, Ito M, Ito K, Yun J, Miura R, Tominaga T (2008) Floristic compositions of Inner 23 Mongolian grasslands under different land-use conditions. Grassl. Sci. 54: 173-178.

24 Ao M, Miura R, Tominaga T (2009) Root and rhizome systems of perennial grasses 
1 grown in Inner Mongolian grassland, China. Grassl Sci 55: 187-192.

2 Ashby WC, Hellmers H (1955) Temperature requirements for germination in relation to

3 wild-land seeding. J Range Manag 8: 80-83.

4 Baskin CC, Baskin JM (2001) Seeds: Ecology, Biogeography, and Evolution of $5 \quad$ Dormancy and Germination. Academic Press, San Diego, 1-666.

6 Bewley JD, Black, M (1982) Physiology and Biochemistry of Seeds. 2. Springer-Verlag, $7 \quad$ Berlin. 1-375.

8 Graves S, Piepho HP, Selzer L (2006) multcompView: Visualizations of Paired 9 Comparisons. (available from URL: http://www.r-project.org/)

10 Grilz PL, Romo JT, Young JA (1994) Comparative germination of smooth Brome and 11 plains rough fescue. Prairie Naturalist 26: 157-170.

12 Ito M, Ao M, Ito K (2006) Inner Mongolian grasslands: situation and concern. $J$ Weed 13 Sci Tech 51: 256-262. (In Japanese)

14 Jiang G, Han X, Wu J. (2006) Restoration and management of the Inner Mongolia 15 grassland require a sustainable strategy. AMBIO 35: 269-270.

16 Kawada K, Wuyunna, Nakamura T. (2011) Land degradation of abandoned croplands in 17 the Xilingol steppe region, Inner Mongolia, China. Grassl Sci 57: 58-64.

18 Liu GS, Qi DM, Shu QY (2004) Seed germination characteristics in the perennial grass species Leymus chinensis. Seed Sci Tech 32: 717-725.

20 Liu GX, Han JG (2007) Influence of grassland gap on seedling establishment of Leymus 21 Chinensis (Trin.) Tzvel. Rangel Ecol Manag 60: 624-631.

22 Liu GX, Han JG (2008) Seedling establishment of wild and cultivated Leymus chinensis 23 (Trin.) Tzvel. under different seeding depths. J Arid Environ 72: 279-284.

24 Ma HY, Liang ZW, Wang ZC, Chen Y, Huang LH, Yang F (2008) Lemmas and 
1 endosperms significantly inhibited germination of Leymus chinensis (Trin.) Tzvel. 2 (Poaceae). J Arid Environ 72: 573-578.

3 Ma HY, Lü BS, Yang HY, Yan C, Liang ZW (2012) Responses of seed germination of

4 Leymus chinensis to environmental factors in degraded grassland on Songnen Plain

$5 \quad$ in China. Chin J Pl Ecol 36: 812-818. (In Chinese with English abstract.)

6 McDonald MB, Copeland LO (1989) Seed Science and Technology Laboratory Manual.

7 Iowa State University Press, Ames, Iowa, 1-231.

8 McElgunn JD (1974) Germination response of forage grasses to constant and 9 alternating temperatures. Can J Pl Sci 54: 265-270.

McGinnies WJ (1960) Effects of moisture stress and temperature on germination of six 11 range grasses. Agron J 52: 159-162.

12 Meyer N (2006) Desertification and restoration of grasslands in Inner Mongolia. $J$ $13 \quad$ Forestry 104: 328-331.

14 Newell LC (1973) Smooth bromegrass. In: Forages: The Science of Grassland 15 Agriculture 3rd edition (Eds Heath ME, Metcalfe DS, Barnes RE), Iowa Univ. Press, 16 Ames, Iowa, USA, 254-262.

17 Plummer AP (1943) The germination and early seedling development of twelve range grasses. Agron J, 35: 19-34.

Pons TL (2000) Seed responses to light. In: Seeds: the Ecology of Regeneration in Plant Communities. 2nd Edition (Ed. Fenner M), CABI Publishing, Oxon, 237-260.

21 R Development Core Team (2008). R: A Language and Environment for Statistical 22 Computing. R Foundation for Statistical Computing, Vienna, available from URL: http://www.r-project.org/ [accessed 2012].

24 Rogler GA (1973) The wheatgrasses. In: Forages: The Science of Grassland Agriculture 
1 3rd edition (Eds Heath ME, Metcalfe DS, Barnes RE), Iowa Univ. Press, Ames, Iowa, $2 \quad$ USA, 221-230.

3 Shao XQ, Wang K, Dong SK, Huang XX, Kang MY (2006) Regionalisation of suitable

4 herbages for grassland reconstruction in agro-pastoral transition zone of northern $5 \quad$ China. $N$ Z J Agric Res 49: 73-84.

6 Smoliak S, Johnston A (1968) Germination and early growth of grasses at four 7 root-zone temperatures. Can J Pl Sci 48: 119-127.

8 Yiruhan, Hayashi I, Nakamura T, Shiyomi M (2001) Changes in floristic composition of 9 grasslands according to grazing intensity in Inner Mongolia, China. J Japan Grassl 10 Sci 47: 362-369.

11 Zhang WD, Bi JJ, Ning TY, Liu XL, He MR (2006) Effects of temperature, light and 12 other treatments on seed germination of Leymus chinensis. Can J Plant Sci 86: $13 \quad 143-148$.

14 


\section{Figure legends}

2

3 Figure 1 Time course of germination of four grass species at six constant temperatures.

4

5 Figure 2 Germination of the seeds of four grass species as affected by temperature and

6 light. Error bars, shown only where larger than the symbols, indicate standard errors of 7 the mean.

8

9 Figure 3 Germination of four grass species under constant and alternating temperatures.

10 In each species, columns with different letters are significantly different according to

11 Tukey's HSD test $(\mathrm{P}<0.05)$.

12

13 Figure 4 Percentages of germinated, dormant, and dead seeds among 1-year-old (2006)

14 and current-year (2007) seeds of four grass species.

15

16 Figure 5 Effect of dehusking and scarification on the germination of Leymus chinensis

17 seeds. Error bars indicate standard errors of the mean. 

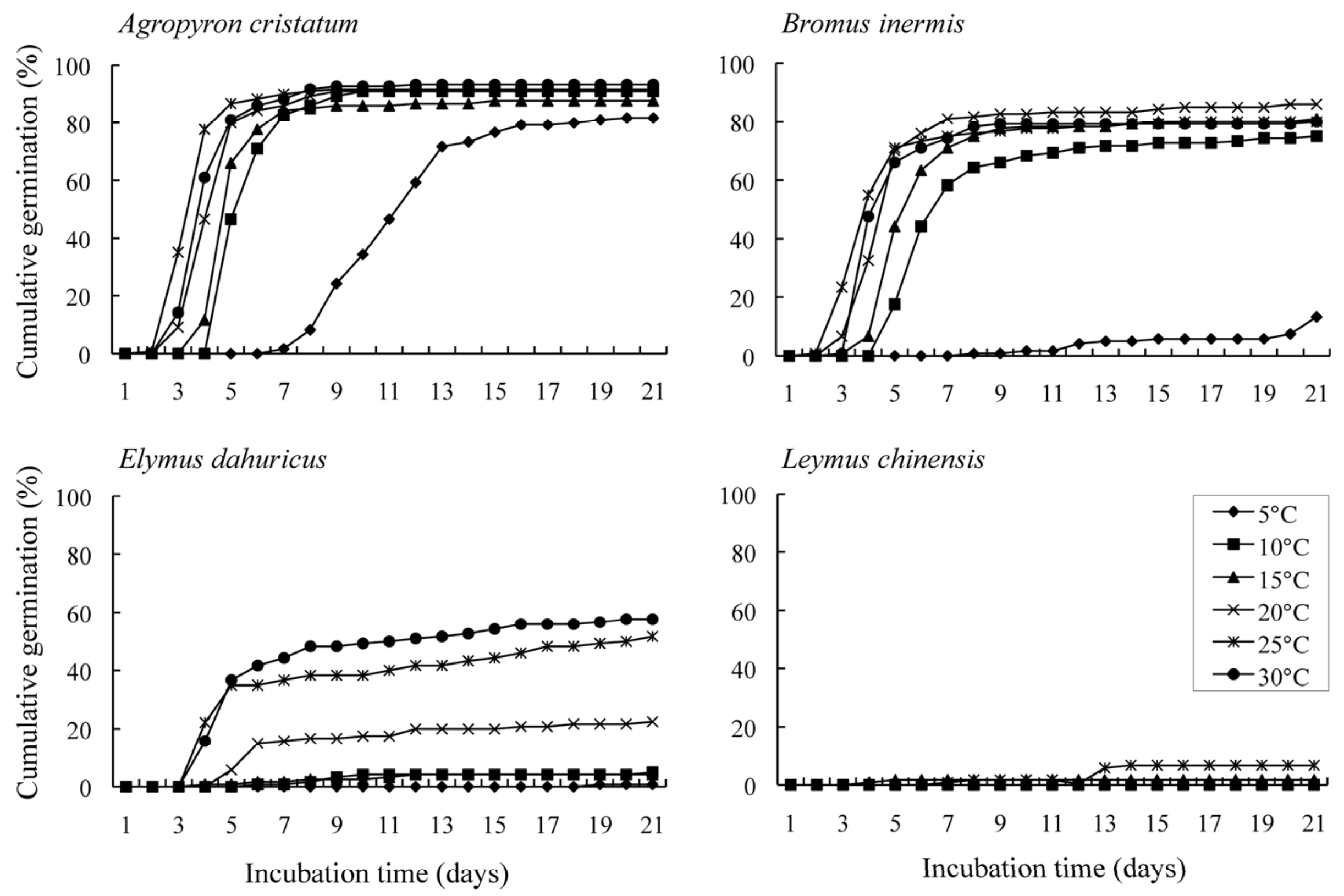

Figure 1 
Agropyron cristatum
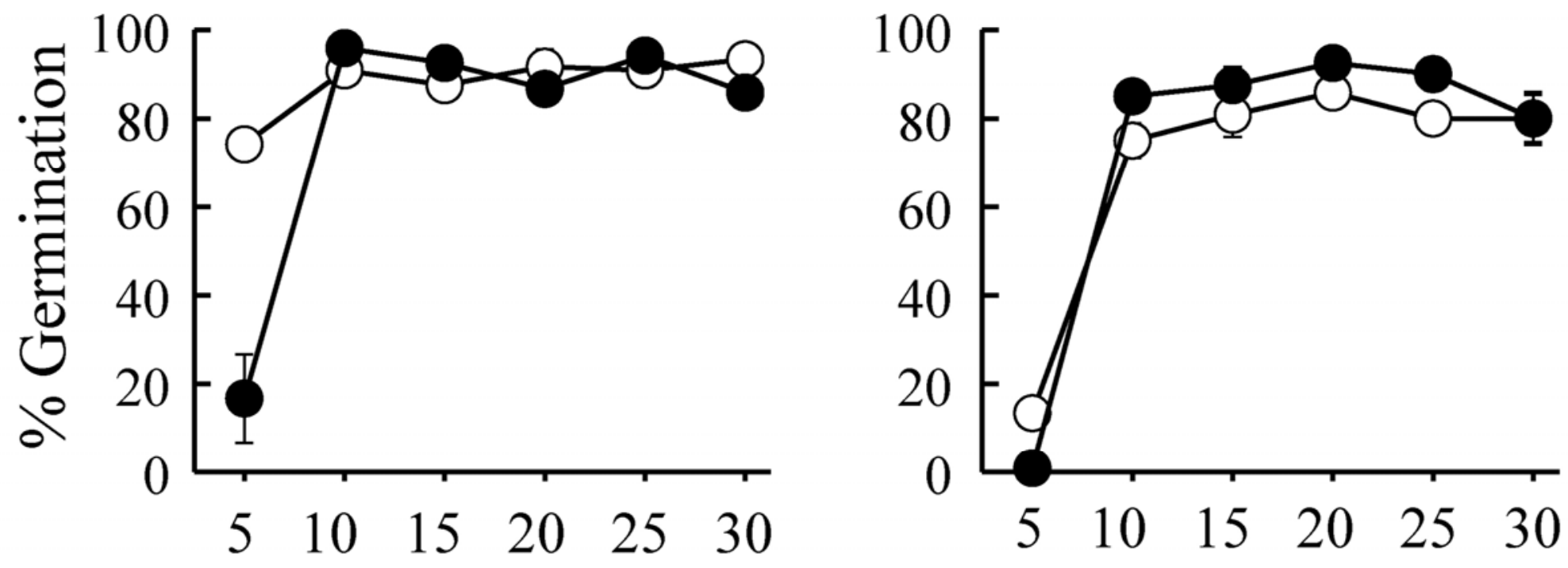

Elymus dahuricus
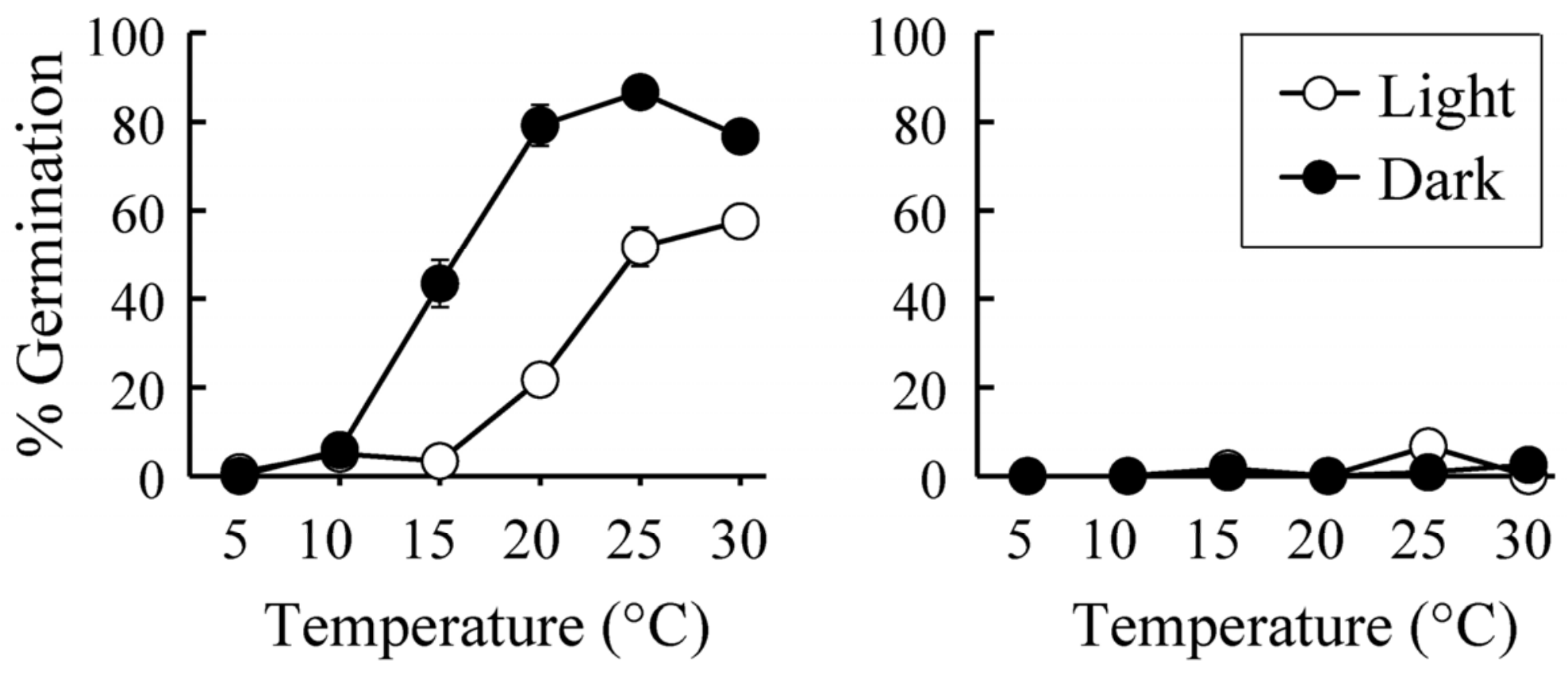

Figure 2 


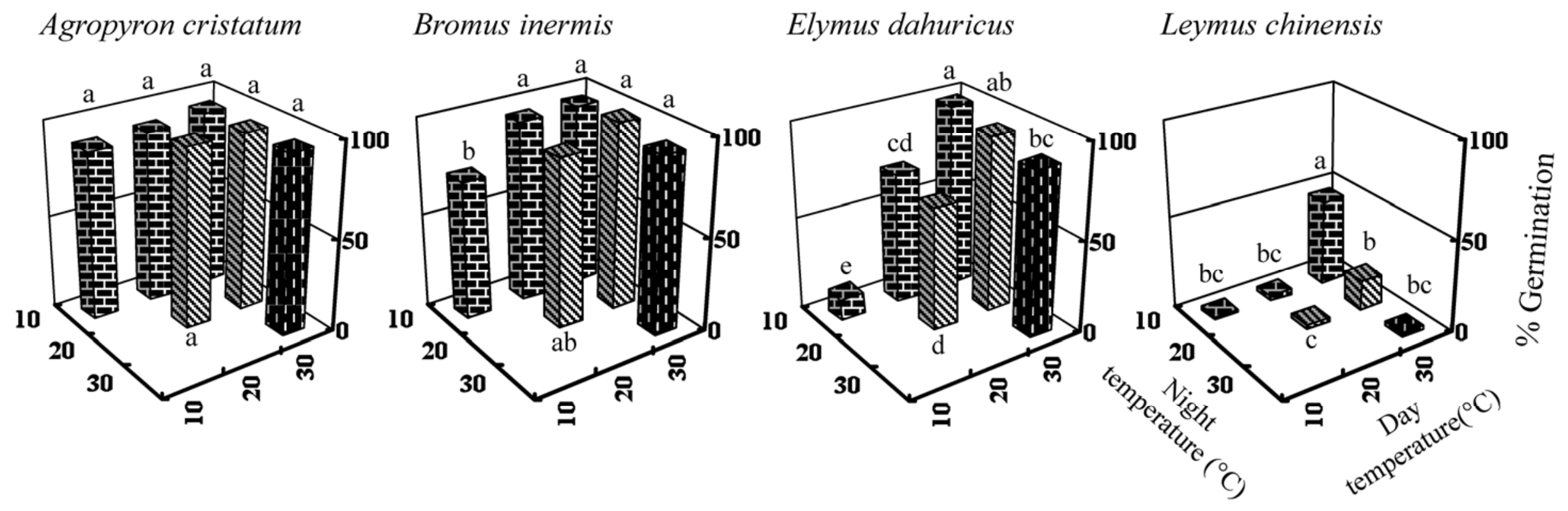

Figure 3 


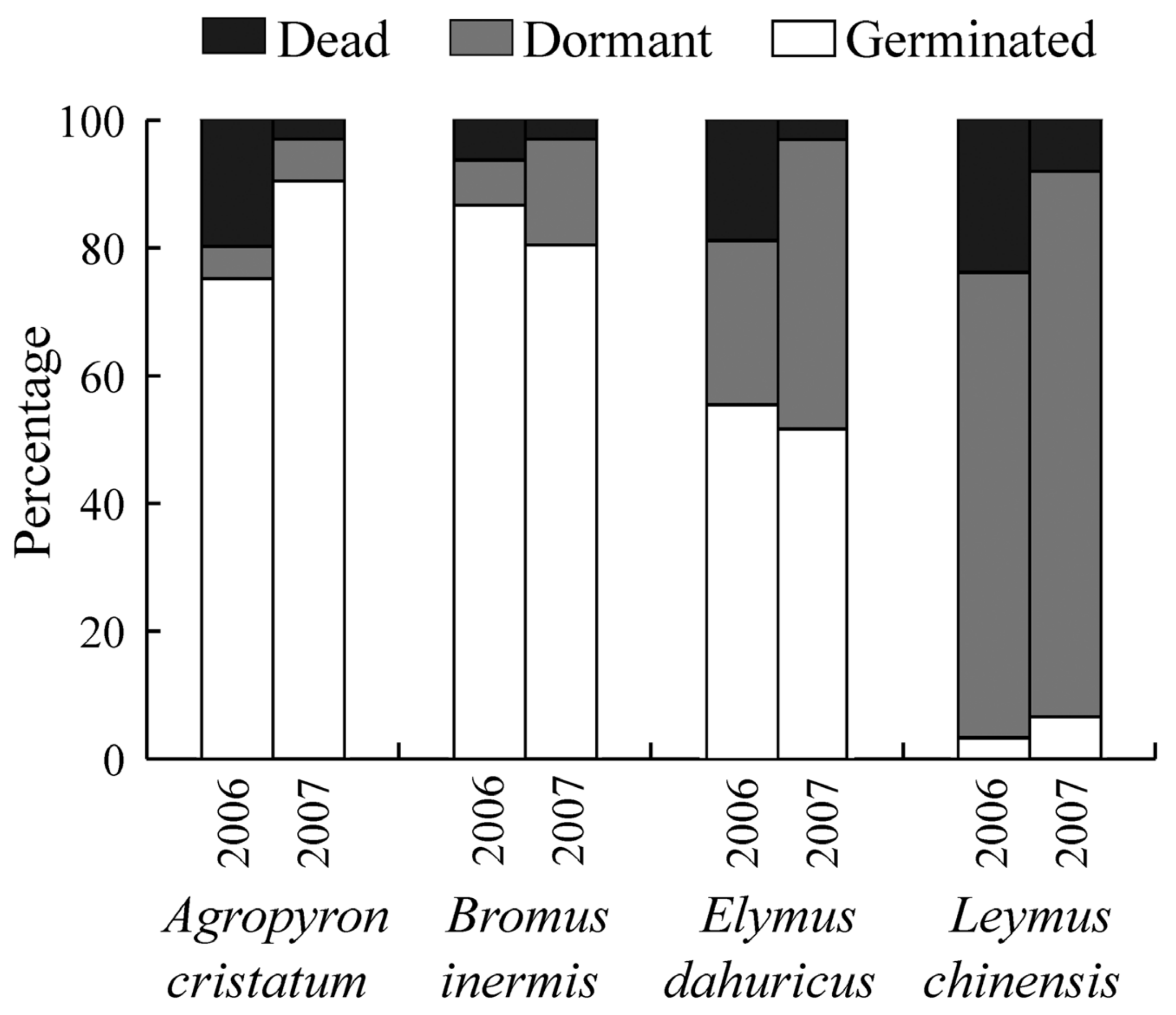

Figure 4 


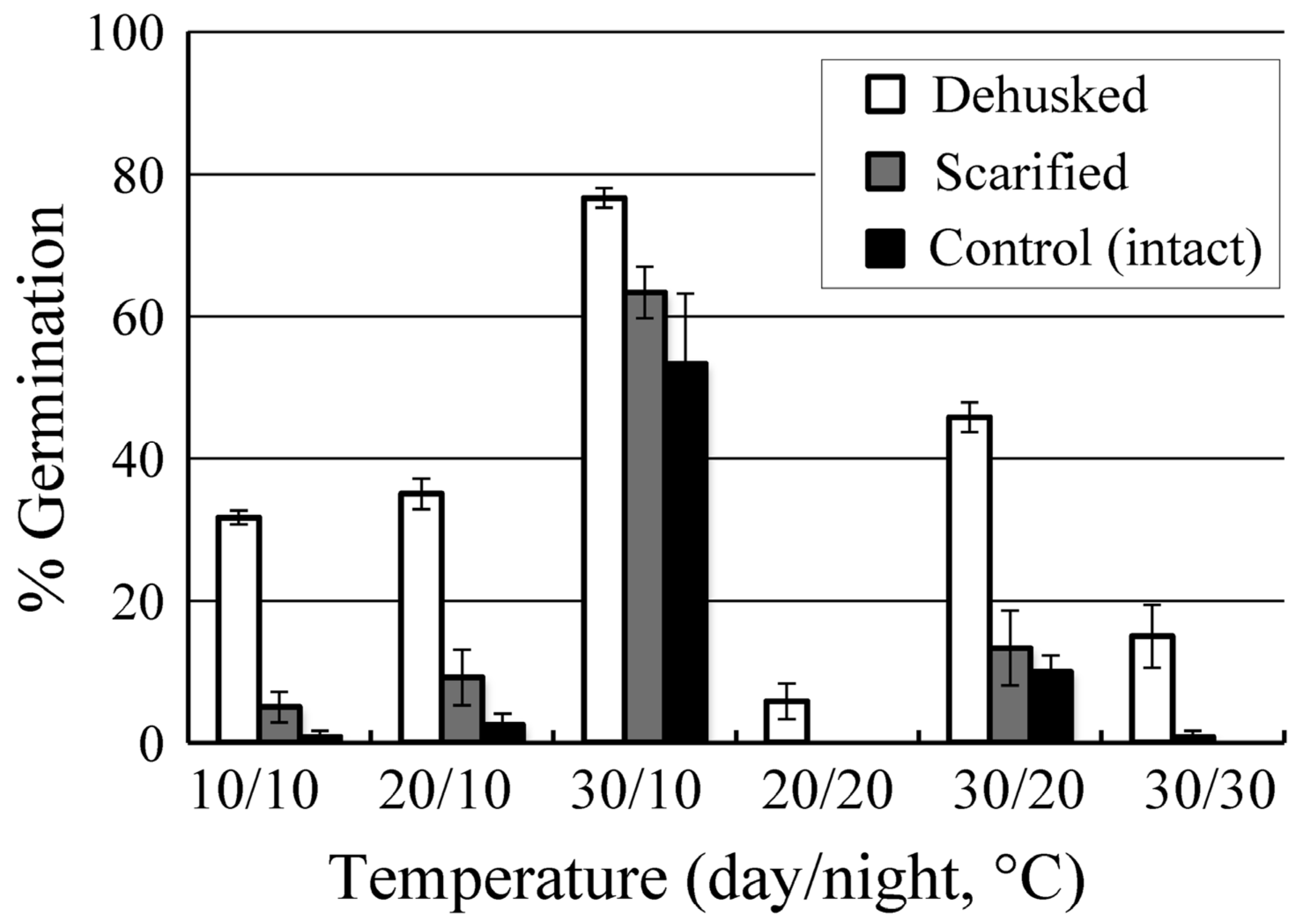

Figure 5 